\title{
BNREL
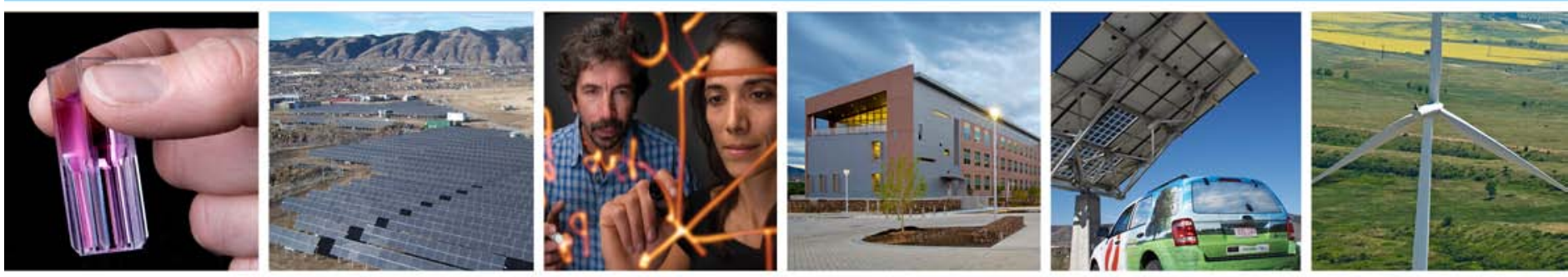

\section{Effective Ancillary Services Market Designs on High Wind Power Penetration Systems}

\section{Preprint}

\section{Erik Ela}

National Renewable Energy Laboratory

Brendan Kirby

Independent Consultant

Nivad Navid

Midwest Independent System Operator

J. Charles Smith

Utility Wind Integration Group

To be presented at the IEEE Power and Energy Society General Meeting

San Diego, California

July 22-26, 2012

NREL is a national laboratory of the U.S. Department of Energy, Office of Energy

Efficiency \& Renewable Energy, operated by the Alliance for Sustainable Energy, LLC.

Conference Paper

NREL/CP-5500-53514

December 2011

Contract No. DE-AC36-08G028308 


\section{NOTICE}

The submitted manuscript has been offered by an employee of the Alliance for Sustainable Energy, LLC (Alliance), a contractor of the US Government under Contract No. DE-AC36-08GO28308. Accordingly, the US Government and Alliance retain a nonexclusive royalty-free license to publish or reproduce the published form of this contribution, or allow others to do so, for US Government purposes.

This report was prepared as an account of work sponsored by an agency of the United States government. Neither the United States government nor any agency thereof, nor any of their employees, makes any warranty, express or implied, or assumes any legal liability or responsibility for the accuracy, completeness, or usefulness of any information, apparatus, product, or process disclosed, or represents that its use would not infringe privately owned rights. Reference herein to any specific commercial product, process, or service by trade name, trademark, manufacturer, or otherwise does not necessarily constitute or imply its endorsement, recommendation, or favoring by the United States government or any agency thereof. The views and opinions of authors expressed herein do not necessarily state or reflect those of the United States government or any agency thereof.

Available electronically at http://www.osti.gov/bridge

Available for a processing fee to U.S. Department of Energy and its contractors, in paper, from:

U.S. Department of Energy

Office of Scientific and Technical Information

P.O. Box 62

Oak Ridge, TN 37831-0062

phone: 865.576.8401

fax: 865.576 .5728

email: mailto:reports@adonis.osti.gov

Available for sale to the public, in paper, from:

U.S. Department of Commerce

National Technical Information Service

5285 Port Royal Road

Springfield, VA 22161

phone: 800.553 .6847

fax: 703.605.6900

email: orders@ntis.fedworld.gov

online ordering: http://www.ntis.gov/help/ordermethods.aspx

Cover Photos: (left to right) PIX 16416, PIX 17423, PIX 16560, PIX 17613, PIX 17436, PIX 17721

Printed on paper containing at least $50 \%$ wastepaper, including $10 \%$ post consumer waste. 


\title{
Effective Ancillary Services Market Designs on High Wind Power Penetration Systems
}

\author{
Erik Ela, Member, IEEE, Brendan Kirby, Senior Member, IEEE, Nivad Navid, Senior Member, IEEE, \\ and J. Charles Smith, Senior Member, IEEE
}

\begin{abstract}
Ancillary services markets have been developed in many of the restructured power system regions throughout the world. Ancillary services include the services that support the provision of energy to support power system reliability. The ancillary services markets are tied tightly to the design of the energy market and to the physics of the system and therefore careful consideration of power system economics and engineering must be considered in their design. This paper focuses on how the ancillary service market designs are implemented and how they may require changes on systems with greater penetrations of variable renewable energy suppliers, in particular wind power.
\end{abstract}

Index Terms-- ancillary services, frequency response, market operations, operating reserves, power system operations, voltage support, wind integration, wind power.

\section{INTRODUCTION}

$\mathrm{R}$ ECENT trends in the power system industry have seen tremendous growth in renewable energy suppliers. Many of these renewable resources are variable generators who have an availability limit that changes through time (variability) and cannot be predicted with perfect accuracy (uncertainty). This variability and uncertainty add to the existing variability and uncertainty of the current systems. This additional variability and uncertainty have unique characteristics and may change the way that system operators maintain a reliable power system. Many entities have been studying these impacts in detail to understand how [1]-[2].

Many areas throughout the world, including the United States, have introduced restructured power systems with wholesale markets for electricity. In the U.S. these have evolved into the standard market design [3]. Energy is sold in forward (e.g., day-ahead markets) and real-time markets and is usually settled at locational marginal prices. To support the scheduling of energy on power systems, operators require ancillary services. Ancillary services may include a number of different operations which include frequency support, voltage support, and system restoration [4]. To encourage the individual participants of the market to provide these services, ancillary services markets were created [5].

E. Ela is with the National Renewable Energy Laboratory in Golden, CO, USA (erik.ela@nrel.gov)

B. Kirby is an independent consultant in Knoxville, TN, USA (kirbybj@ieee.org)

N. Navid is with the Midwest Independent System Operator in Carmel, IN, USA (nnavid@midwestiso.org)

J.C. Smith is with the Utility Wind Integration Group in Kitty Hawk, NC (Charlie@uwig.org)
Many of the ideas behind the complexity of the standard market design were implemented without the idea that variable renewable resources like wind would have such a market presence. The impact can be seen on the energy market, capacity market, ancillary service market, and other potentially new market designs [6]. The impact of wind power on the operating reserve requirements has been studied extensively [7]. Its impact on reactive power reserve and voltage control has also been studied [8]. There has also been research onto possible ways that wind power can actually provide various ancillary services [9]-[11].

This paper will discuss some ideas that the authors have on potential changes, specifically, that the introduction of high penetrations of wind power will have on the ancillary services markets. Section II will discuss the current ancillary services market designs of the U.S. Section III will then discuss some ways that these market designs may change based on changing ancillary services requirements because of higher wind power penetrations. Section IV will discuss potential new market designs that may be needed. Section $\mathrm{V}$ will discuss a case study of a new ancillary services market being designed by the Midwest Independent Transmission System Operator. Section VI summarizes the paper.

\section{Current Ancillary Service Markets}

Ancillary services markets can either be dynamic with hourly or faster prices set based on system conditions, or they can be cost-based where set rates are made in advance to ensure that suppliers are made whole. Many of the ancillary services that assist in active power balance and frequency support will have dynamic markets since they are tied tightly to the energy markets. Other services, like for example black start, will have cost-based services. These services incur little change to system conditions nor are they part of a competitive paradigm. The following ancillary services were represented by FERC in its Order 888 [12] with our definition of how they are or are not represented in ancillary services markets:

1. Scheduling, system control and dispatch: This is the service that the Independent System Operator (ISO) or Regional Transmission Organization (RTO) provides and is not applicable to our discussion on ancillary services market design.

2. Reactive supply and voltage control from generation service: Reactive power supply and voltage control is generally supplied as a cost-based service. 
3. Regulation and frequency response service: Today, regulation is typically supplied and priced by dynamic markets in ISO/RTO regions. It is used to assist in controlling frequency. However, frequency response, as defined by the droop response of governors immediately in response to frequency is generally not included in any dynamic markets nor is it given cost-based rates.

4. Energy imbalance service: Energy imbalance is usually the service of the real-time markets balancing out the imbalance from the forward markets and therefore is priced by the real-time energy markets.

5. Operating reserve - synchronized reserve service: This service is typically supplied and priced by dynamic markets in ISO/RTO regions.

6. Operating reserve - supplemental reserve service: This service is typically supplied and priced by dynamic markets in ISO/RTO regions.

We will focus our attention of the current market designs in this section to the services of regulation (part of service 3 ), spinning reserve (service 5), and non-spinning reserve (service 6 ). We will reintroduce some of the other services later in the paper when discussing the potential for new ancillary services markets. Fig. 1 shows the ISO and RTO regions of North America. Of these regions and at the time of this writing, only the Southwest Power Pool does not currently have ancillary services markets. The remaining regions all have dynamic dayahead and real-time ancillary services markets for regulation, spinning reserve, and non-spinning reserve [13].

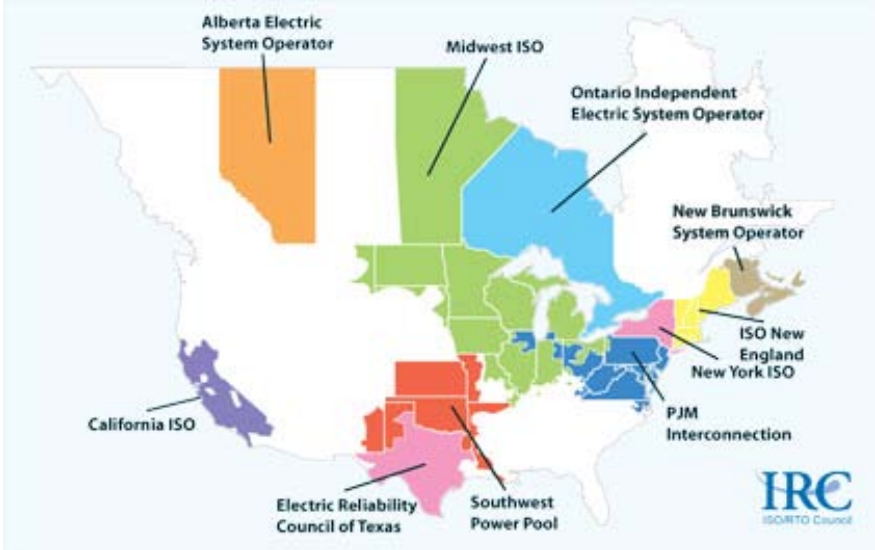

Fig. 1. ISO and RTO regions in North America.

\section{A. Ancillary Services Requirements}

Many of the ancillary services requirements that the ISO (we will use ISO to refer to both ISO and RTO throughout the rest of this paper) will procure in its markets are directed by the reliability requirements. In North America, the reliability requirements are directed by the North American Electric Reliability Corporation (NERC) [14]. These may be further defined by regional reliability organizations, state reliability councils, or the ISO itself. These requirements are usually consistent between day-ahead and real-time markets.

The NERC Disturbance Control Standard (DCS) requires that each balancing area have enough reserve to cover its largest credible contingency. This can include both spinning and non-spinning reserve. Often, spinning reserve and nonspinning reserve are combined to refer to contingency reserve. Although not a NERC requirement, most regions will also require that at least $50 \%$ of this reserve be spinning reserve, meaning it must come from generators online and synchronized to the grid [15]. Also according to the DCS, these reserves must be able to respond within 10 minutes after a contingency. Still other regions have requirements for second contingencies. For example, in the Northeast Power Coordinating Council, a requirement is to procure $50 \%$ of the second largest contingency to be available within 30 minutes [16]. This shows how both quantity and speed requirements must be part of the market clearing engine when each ISO procures its service. Both will affect what resources are selected and what prices are calculated. These particular reserves and reserve requirements are currently not impacted in these systems by the recent growth of wind power.

NERC also requires all balancing area authorities be in compliance with the control performance standards (CPS1 and CPS2). These standards direct the balancing requirements during normal conditions (i.e., not during contingencies). These requirements will give the ISO direction on how much and what type of regulation to procure in the regulation markets. Usually the ISO will base its requirements on time of day, weekday vs. weekend, and season among other things. ERCOT will actually consider the additional wind impact when determining its current requirement [17]. Usually, the regulation requirement must be fully available within the economic dispatch interval, which is typically 5 minutes in U.S. ISOs. Lastly, unlike spinning and non-spinning reserve, the regulation requirement is bi-directional, meaning that both upward and downward capacity must be made available. Interestingly, some regions will combine both services in the market, while others keep them as two separate markets. Table I shows some examples of these requirements [7].

TABLE I

\begin{tabular}{c|c|l}
\multicolumn{2}{c}{ REGULATION MARKETS AND REQUIREMENTS IN VARIOUS ISOS } \\
Region & $\begin{array}{c}\text { Separate/ } \\
\text { Combined }\end{array}$ & \multicolumn{1}{|c}{ Rule } \\
\hline PJM & Combined & $\begin{array}{l}\text { Based on 1\% of the peak load during peak } \\
\text { hours and 1\% of the valley peak during off- } \\
\text { peak hours. }\end{array}$ \\
\hline EYISO & Combined & $\begin{array}{l}\text { Set requirement based on weekday or weekend, } \\
\text { hour of day, and season. }\end{array}$ \\
\hline CAISO & Separate & $\begin{array}{l}\text { Based on 98.8th percentile of regulation utilized } \\
\text { in previous 30 days of same month of previous } \\
\text { year and adjusted by installed wind capacity. }\end{array}$ \\
\hline MISO & Combinated & $\begin{array}{l}\text { Use a requirement floor of 350-MW up and } \\
\text { previous CPS performance, and interchange and } \\
\text { generation schedule changes. }\end{array}$ \\
\hline ISO NE & Combined & $\begin{array}{l}\text { Requirement made once a day based on } \\
\text { conditions and before the day-ahead market } \\
\text { closes. }\end{array}$ \\
\hline Based on month, hour of day, weekday/sat/sun.
\end{tabular}




\section{B. Ancillary Services Pricing}

Generally, the pricing of ancillary services is given by the shadow price of the ancillary services inequality constraint. Therefore, the price would be calculated as the cost of the marginal resource providing the ancillary service. The costs may include the bid-in cost of the resource as well as the lost opportunity cost it has from forgoing the energy market or other ancillary services markets. Opportunity costs usually dominate the pricing of the active-power balancing ancillary services in organized markets (regulation and the contingency reserves). Under most conditions a generator that is supplying spinning reserve, for example, must reduce output and forgo a profitable energy sale in order to stand ready to respond to a contingency. If that generator's variable fuel and maintenance cost was $\$ 40 / \mathrm{MWh}$ and the energy market was clearing at $\$ 50 / \mathrm{MWh}$, the market would have to pay at least $\$ 10 / \mathrm{MWh}$ for spinning reserve to make provision of spinning reserve more attractive than the provision of energy. Providing regulation typically includes an additional cost component to cover the reduction in plant efficiency that thermal generators experience when they position their throttling valves to enable fast and controlled regulation response. It may also include additional maintenance costs from the increased wear and tear of operating in this mode.

Spinning and non-spinning reserves are typically very low cost when the power system is at minimum load since there are typically numerous generators operating below full load that have the ability to rapidly increase output. There is no opportunity cost for these generators. Regulation prices do reflect opportunity costs at system minimum load however. Regulation capable generators would typically be operating at minimum capacities themselves, if they were still on line. They must increase output above the minimum capacity in order to be able to regulate down. Fig. 2 shows the regulation price an example generator would have to receive to prefer providing regulation as opposed to providing energy. This example generator has an \$18/MWh fuel and variable operating and maintenance cost when operating at minimum load. If the system energy cost is below $\$ 18 / \mathrm{MWh}$ the generator would prefer to shut down. The black line shows the regulation price as a function of the energy price if the unit is forced on just to provide regulation. The dotted blue line shows the regulation price if the unit is being held on at minimum load because it is unable to cycle off.

Calculating ancillary services prices based on generator opportunity costs is straightforward. Including generator efficiency penalties is also reasonably straightforward. Operators of organized markets are able to perform the calculation for the generators, allowing the generators to simply provide their costs and letting the market clearing process generate the appropriate energy and ancillary service prices. Further, the market operator can co-optimize all of the generator bids such that it simultaneously guarantees each generator the maximum profit and minimizes the overall cost of procuring energy and ancillary services. Each generator submits its energy cost and operating limitations and the market clearing process schedules each generator for the optimal mix of energy and ancillary service production each hour.

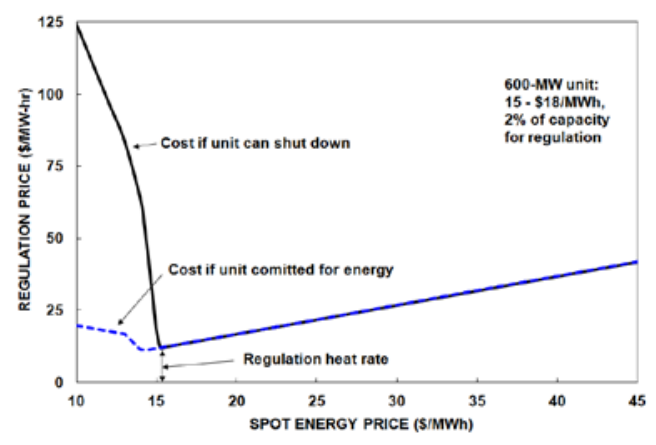

Fig. 2. The opportunity cost of providing regulation depends on the price of energy and the generators variable O\&M cost.

Co-optimization works well for generators but it often does not work for responsive loads. It is difficult to calculate the responsive load's opportunity cost because it depends on more than the energy price. Further, unlike most generators many loads have a rising response cost. There may be little cost for providing 30 minutes of spinning reserve response but there may be a very large cost if the duration is extended to six hours of energy. Co-optimizing reserves into energy does not work for these resources. Energy-limited storage, which can provide excellent regulation but is unable to provide energy, is similarly restricted.

\section{Other requirements}

It is important to briefly mention some other requirements that are in existence in today's ancillary services market designs. Many regions have some constraints on what resources can currently provide ancillary services. For example, in ERCOT, a maximum of $50 \%$ of the responsive reserve service (contingency reserve) can be supplied by demand response resources [17]. Also, in most if not all of the ISOs, variable renewable resources (wind and solar) are precluded from providing ancillary services.

A second important consideration of many of the ancillary services market designs is a location-based requirement. Many ISOs, especially large transmission constrained systems, will require certain portions of their contingency reserve to come from certain parts of the grid. For example, import constrained pockets will require that a certain portion of the contingency reserves that they procure come from within the pocket to ensure that the area can receive the reserves when transmission is limited. Some examples of regions that have these locational requirements are MISO, PJM, CAISO, NYISO, and ISO-New England. Regulation markets, however, are usually not constrained by location. Since regulation deployments are of a shorter timeframe, their impact on transmission constraints is of less consequence.

\section{Ancillary Services Cost Allocation}

Ancillary services costs are not typically allocated based on cost causation. Instead, they are socialized based either on 
energy consumption or demand. This is in spite of the fact that some customers differ dramatically in their ancillary service consumption [18]. One customer is responsible for half of the regulation burden in a $30-\mathrm{GW}$ BA yet pays for only $3 \%$ of the ancillary service cost through the bundled rate. There have been recent efforts to assess specific ancillary service charges on variable renewable suppliers even though the impact of nonconforming loads is typically significantly higher.

\section{Potential Changes to the Existing Designs}

Most of these existing ancillary services markets have changed only slightly if at all since their inception. However, as new changes to the requirements are made to ancillary services as variable renewable generation enters the grid, these changes must be incorporated in the ancillary services markets. The changes that may seem like simple adjustments to the requirements can have unintended consequences when ensuring they are represented in the market design.

In some recent wind integration studies, the changes to the reserve requirements have been analyzed to see how the introduction of up to $30 \%$ wind and solar on large portions of the Eastern and Western Interconnections would impact the ancillary services requirements [19]-[20]. Each of these studies concluded that the reserve requirements should not be static, but should in fact change based on the predicted conditions of the system. For example, the predicted wind power would impact the amount of variability on the system (see Fig. 3) and therefore, this would change the reserve need on the system. In current systems, this is rarely done. By having a requirement that changes each hour based on predicted conditions, market participants would have to plan ahead to understand what the ancillary services demand might be, similar to how they anticipate the load demand.

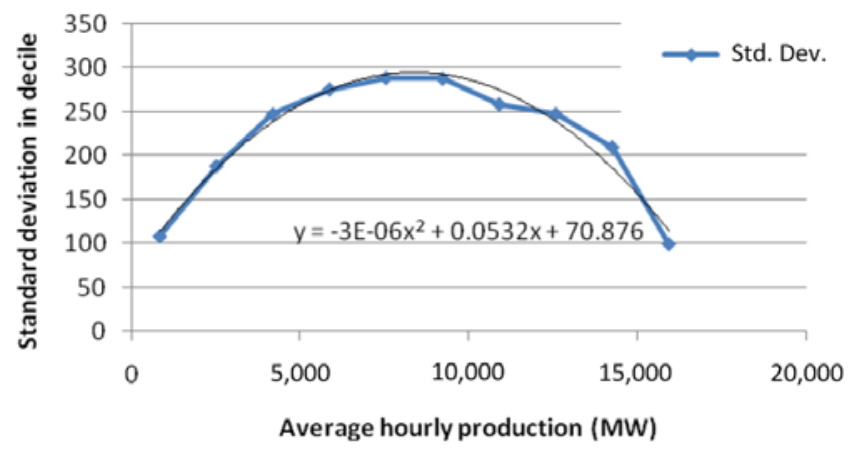

Fig. 3. Variability of wind as a function of its hourly production level.

In today's systems, the operating reserve demand must usually be kept constant between the day-ahead and real-time markets. This is because the rules that guide operating reserves are such that the requirements would not change as one gets closer to real-time. For example, the probability of a large generator contingency occurring generally does not change since it cannot be better predicted closer to real-time. However, operating reserves that are held to account for the uncertainty of wind power may not be the same [21]. The operator has more information as the system gets closer in real-time and more confidence in scheduling generation, which means less operating reserves would be required. The reserve demand would therefore change between day-ahead and realtime markets, similar to how load demand does today. Some care should be taken to limit market power and ensure inefficiency does not result. For example, if the reserve demand is always higher in the day-ahead, there may be large price premiums for the reserve market in the day-ahead which could lead to diverging prices between the day-ahead and realtime markets. To account for this in the energy market, virtual trading is introduced. Some careful research should be undertaken to determine the practicality of virtual trading in the ancillary services market.

Lastly, the technologies that participate in the ancillary services markets are ever changing. Today, more and more demand response resources are beginning to offer in to contingency reserve markets and regulation markets. More recently, some new limited energy storage resources are participating in the regulation markets [22]. Certain rules that focused on generating technologies had to be changed to allow for these new technologies to participate given their unique characteristics. In the future it is quite possible that more variable renewable technology like wind power may also be participating in certain ancillary services markets. Some analysis has shown this to be economic, especially in regulation markets [23]-[24]. Ideally, the ancillary service requirement is based on the need of that service and not tailored to the conventional market participants that are currently providing the service.

\section{Potential For New Ancillary Services Market DESIGNS}

The set of ancillary services originally defined in FERC Order 888 that have developed into ancillary services markets has stood the test of time quite well. Regulation, spinning reserve, and non-spinning reserve cover most of the activepower balancing requirements for both normal and contingency conditions. Changing conditions, driven largely but not exclusively by the increase in variable renewable generation, may be creating the need for new ancillary services: following, frequency responsive reserve, inertial response, and reactive power support. All four appear to be amenable to market provision as ancillary services but the reliability requirements could also be partially or wholly addressed through interconnection requirements instead.

\section{A. Following}

Regulation provides the minute-to-minute balancing during normal conditions. Regulation operates in a time frame that is faster than the fastest energy market or than the economic dispatch scheduling interval. As such, regulation is a somewhat different service in regions with 5-minute energy markets than it is in regions that have hourly scheduled energy transactions.

FERC did not establish a following or load following service but instead, presumably, expected that the energy 
market would inherently provide load following, and this is what normally does occur today. Following is normally provided by the economic movement of the conventional generators as part of providing energy. This can be from the economic dispatch of the vertically integrated utilities' generation or from the hourly and sub-hourly energy markets of ISOs. In both cases, the conventional generation fleet was typically designed and built with sufficient flexibility to follow the net load (load minus variable renewable) daily load cycle. As net load rises or falls, the system operator simply commits and dispatches the marginal units (the most expensive generators currently operating) up or down to follow the net load. There is no explicit cost for this following service and, as mentioned, it was not identified as an ancillary service by FERC in Order 888, though discussions from some ISOs have occurred about establishing separate markets for its service.

With increasing penetrations of variable renewables, the required ramp rate can exceed the ramping capability of the conventional generation fleet under some conditions [25]. Fig. 4 shows an overly simplified hypothetical example to illustrate this concept. In this example there is plenty of low-cost $\$ 10 / \mathrm{MWh}$ generation available to meet the load. This low-cost generation has a slow ramp rate capability of $1 \mathrm{MW} /$ minute, however. When the load ramps up by $300 \mathrm{MW}$ in 30 minutes (10 MW/minute) the economically preferred generation cannot keep up. A faster ramping, but more expensive generator must be started and run for 3 hours simply to follow the fast load ramp. Eventually the low cost generation catches up and the ramping generator can be turned off.

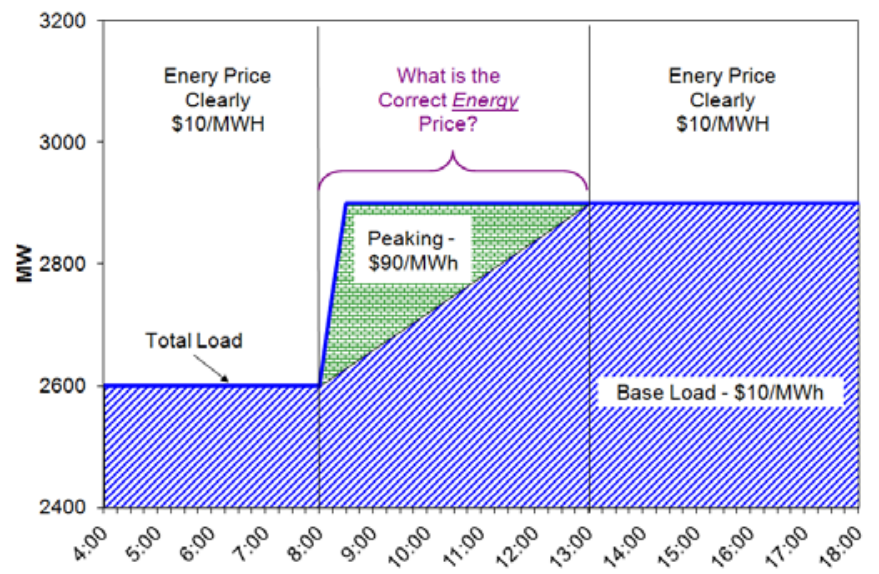

Fig. 4. A Following ancillary service is required when net load ramping requirements exceed the ramping capabilities of the energy producing generators.

In organized energy markets the lack of a separate following service can result in a distortion of the energy market clearing price: the entire $2600 \mathrm{MW}$ energy market may clear at $\$ 90 / \mathrm{MWh}$ from 8:00 to 13:00 even though only 300 MW of ramping capacity is needed in the above example. In vertically integrated utility areas this results in the deployment of generation out of merit order. Regulation should not be used to respond to this event because the event is slow relative to the energy scheduling interval. Using contingency reserves is similarly inappropriate. Establishing an explicit following ancillary service may be appropriate if this type of event happens more than vary rarely.

Historically a separate following reserve has not been required in North America. Increased penetration levels of variable renewable generation can increase the net load ramping requirements, however, and both MISO and CAISO have recognized the need to assure that sufficient ramping capability is available when needed (the former described later). It may be appropriate to more generally define a following service that is similar to regulation, but slower. The requirement, or the compensation, may be zero during the many hours when the energy producing fleet inherently has sufficient ramping capacity to follow the net load. There is little need to create either an additional service or, ultimately, an additional payment for times when something is already in sufficient supply.

Like regulation, following requirements would be measured in MW of ramping capacity within a specific time frame. Accuracy of responding to system operator commands would be measured. Also like regulation, power system following requirements will likely vary hourly depending on system load and variable resource output. The cost to provide following will likely be more volatile than regulation and often zero.

\section{B. Frequency Responsive Reserve}

Spinning reserve and non-spinning reserve are usually defined as services which respond to contingency events. Both reserves must be fully deployed within 10 minutes but the required response during the first few cycles or first few seconds is not well defined. Historically this was acceptable because the conventional generation fleet tended to naturally provide the required inertia and governor response. Changes in the generation mix, with electronically coupled generation that has no inherent inertia, and changes in the operating practices of some large conventional generators that effectively eliminate governor response create a reliability concern that may require the addition of two new ancillary services: frequency responsive reserve and inertial response.

Frequency responsive reserve was historically provided by conventional generators with governors. It is an autonomous response triggered by the frequency drop associated with a contingency event itself. While frequency responsive reserve is not yet an ancillary service, WECC has been studying frequency responsive reserve for many years [26]. There is also an established requirement in the continental European Interconnection [27]. It may soon be required in the Eastern Interconnection where governor response has declined significantly due to the economic operating mode of many large conventional generators [28].

Changes in technology make it possible for some responsive load and storage to provide frequency responsive reserve along with generation. Electronically coupled generators often have faster ramp rates and greater flexibility to tailor their frequency response to the requirements of the power system. These changes in both the power system requirements for frequency responsive reserve and the increased number of resources that are potentially capable of 
providing the response may make establishing a new ancillary service market appropriate. Ancillary service requirements would be specified in terms of response need rather than in terms of interconnection requirements for generators. WECC outlined a method for determining the required amount of frequency responsive reserve based on the governor droop and the settings of the under frequency load shedding relays that it is desirable to avoid tripping. The droop and response speed must also be defined for the ancillary service providers.

\section{Inertial Response}

Even though there appears to be no reason that ancillary services markets cannot provide frequency responsive reserve service, there is still some thought that this service ought to be an inherent generation feature that is specified through the interconnection requirements. This line of thinking is driven in part by the recognition that frequency response is critical for the stable and reliable operation of a power system, and ought not to be left to the vagaries of the market. This also carries over to the provision of an even faster responding characteristic of conventional generation, inertial response.

As an increasing share of energy is provided from variable generation with no inherent inertial response, there is a concern that when fossil generation is pushed out of the market to make room for the renewable generation, the system will be less stable due to the lower inertia, thereby allowing the frequency to decline faster during the first swing, bringing the system closer to the first step of under-frequency load shedding or instability. Detailed system simulations of WECC [29] have shown that during the most stressed system conditions - those being very light load periods during spring or fall nights with high wind plant output resulting in some fossil units being decommitted - there is a noticeable degradation in the system frequency response following a disturbance. There may be insufficient fossil-fueled generation remaining on the system to provide adequate inertial response in the event of a fault. The severity of the disturbance is a function of the amount of wind capacity on the system and the amount of fossil-fueled generation decommitted. The simulations show that it is economically and technically possible to provide an emulated inertial response from the wind plants as good as or better than the response in a no-wind case.

Wind turbines connected to the system through a power electronic converter are capable of providing an inertial response. The converter controls can be programmed to apply a retarding torque to the rotating shaft during a frequency disturbance to extract energy and emulate the behavior of inertia. This topic was brought to the fore with the requirement in a Hydro Quebec procurement request for 2,000 MW of wind turbines in 2005, requesting wind turbine behavior representative of a machine with an inertia constant of 3.5 seconds [30].

Unlike a wind turbine, a PV cell has no inertia, and cannot provide an inertial response on its own. However, a fastacting storage device like a flywheel or a battery could certainly be programmed to provide this service. There appears to be a good possibility that certain fast-acting load could also provide a similar service.

There is an ongoing discussion over whether to trust the provision of inertial response to the market, or to mandate it through the process of interconnection requirements or grid codes. Until more experience has been gained with these alternative approaches to providing inertial response to the system, it is likely that a preference will be shown for this service, which is so important to system reliability, to be required through grid codes rather than left to a new ancillary service market design.

\section{Reactive Power Support/Voltage Control}

Reactive power is required to maintain voltages within acceptable limits throughout the power system [31]. Dynamic reactive power (reactive power that can be controlled rapidly and accurately) is required to respond to contingencies and to shifts in load and generation. FERC defined "Reactive Supply and Voltage Control from Generation or Other Sources" as an ancillary service and required transmission providers to provide it to transmission customers.

While the supply of dynamic reactive power is a very real physical function, the payments for the service are more of an accounting mechanism that helps to recover costs. This is because reactive power does not travel far through the transmission system and it must be supplied near where it is needed. This largely prevents markets from being used to select alternative dynamic reactive reserve providers since the location constraint highly limits the competition to provide the service. Instead, utilities typically require generators to provide an amount of dynamic reactive power capability which is then controlled by the system operator as a condition of interconnection. That said, other devices are also capable of providing dynamic reactive power and it may be appropriate to incentivize them to do so. Any device with a solid-state interface with the power system (PV, storage, variable frequency drives, etc.) can be designed to provide excellent dynamic reactive power and voltage control.

\section{New Ancillary Service Market Case Study}

Occasionally, the current market designs lead to short duration price volatility that indicate desired market actions but challenge the reaction times of the market participants. Among the variety of reasons for such price spikes are temporary scarcity conditions created by resource ramp shortages. The main causes of ramp shortages in real time include the forecasted variability of load, interchange transactions and non-controllable variable energy resources at or beyond the dispatch horizon and the uncertainty associated with the forecasts and generating unit deviations from their set points. Higher penetration levels of renewable resources including some of the SMART Grid initiatives or technologies intensify this problem.

What is required is a comprehensive approach in market clearing processes to address the required resource ramp 
capability to cover the multiple sources of variability and uncertainty. This approach has recently been taken at the Midwest ISO [32]. The market clearing process should manage the required level of flexibility among the generation resources by ensuring adequate flexible capacity is available and sending appropriate price signals to provide incentive for resources to continue offering their flexibility.

The proposed approach manages the ramp capability from controllable resources responding to dispatch instructions in a way that better positions (pre-position / pre-ramp) them to be able to respond to variations and uncertainty in net load. The response available with the defined ramp capability is depicted in Fig. 5.

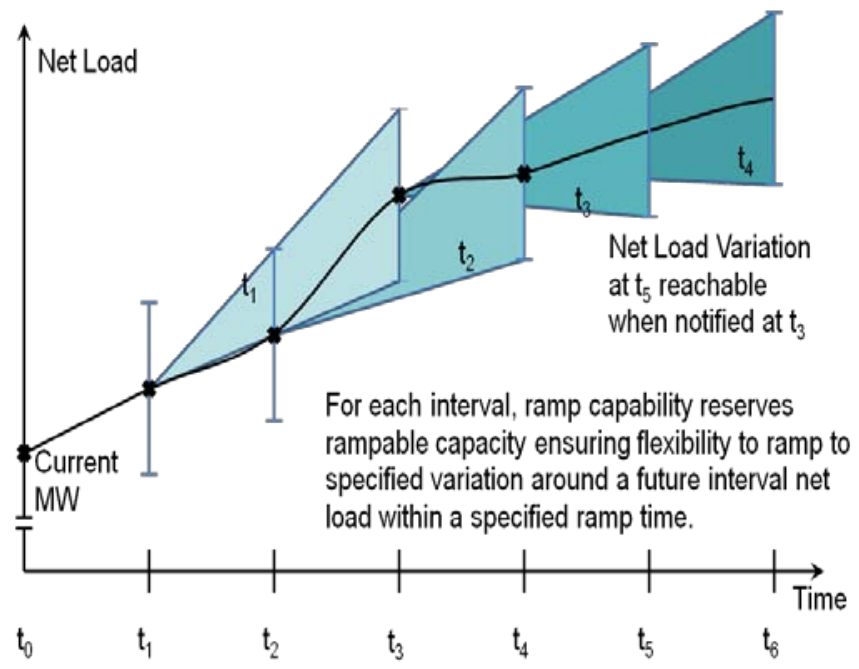

Fig. 5. Up and Down Ramp Capability in SCED.

\section{A. Pricing}

Two options are introduced for pricing these products in Day Ahead and Real Time. The first option is based on the opportunity cost for not using participating resource capacity for providing other products. The next option is to allow qualified resources to provide a separate availability offer for each ramp product. The optimization process in DA and RT will clear these products with a system level or zonal level cleared prices. The selected resources will be paid the cleared price and the opportunity cost. Similar to conventional ancillary services, the interactions between the two market layers (DA and RT) are considered for ramp products. Furthermore, a demand curve for each product is considered restricting the cleared prices.

\section{B. Payments}

Awarded resources will be paid the cleared price both in DA and RT. If the cleared amount is different in DA and RT, the resource will sell or buy the ramp capability to/from market. These resources are subject to real time monitoring of their obligations and will be penalized if they do not perform within the pre-specified limits. The make whole payment procedure is extended to cover the ramp products.

\section{Charges}

Similar to other ancillary services, load will be responsible for charges. The amount paid in DA and RT markets to resources for ramp products will be distributed among loads in the system (or zonal) level based on their load level. As an alternative a different approach based on causation of variability and uncertainty is considered to charge not only load, but other variable generation resources and interchanges. This approach will not be in place initially, however.

\section{Deployment}

The main difference between conventional ancillary services and the ramp products are in the deployment process. There is no separate deployment mechanism for ramp products. The dispatch process in the RT market acts as the deployment process. It withholds the rampable capacity for the future intervals and in the meantime deploys what is necessary for the next interval.

\section{E. Resource participation}

All qualified dispatchable generation resources can participate in Up Ramp and Down Ramp products. However, renewable resources can participate in Down Ramp markets, the demand response can participate in Up ramp markets and the storage resources can participate in both markets.

\section{SUMMARY}

This paper describes the ancillary services markets and how they are impacted by variable renewable resources such as wind power. Many of the initial designs of electricity markets did not incorporate the unique characteristics of variable generation. The ancillary services markets are no exception. Potential changes to the existing ancillary services markets are likely to occur due to the changing requirements of those ancillary services. The requirements that change should be carefully considered to eliminate any unintended consequences. The market design rules guiding the ancillary services markets should not preclude technologies that can provide the desired need. This may soon include ancillary services being provided by variable renewable resources. Lastly, careful consideration should evaluate system needs that may currently be supplied without market incentives to understand if new ancillary services markets are needed to provide the needed services at lowest cost.

\section{REFERENCES}

[1] J. C. Smith, M. Milligan, E. Demeo, and B. Parsons, "Utility wind integration and operating impact state of the art," IEEE Transactions on Power Systems, vol. 22, pp. 900-908, Aug. 2007.

[2] E. Ela, M. Milligan, B. Parsons, D. Lew, and D. Corbus, "The evolution of wind power integration studies: past, present, and future," Proceedings of IEEE PES General Meeting, Calgary, CA, July 2009.

[3] W. Hogan, Competitive Electricity Market Design: A Wholesale Primer, Cambridge, MA: John F. Kennedy School of Government, Harvard Univ., Dec. 1998.

[4] S. Stoft, Power System Economics. New York: Wiley, 2002. 
[5] H. Singh, A. Papalexopoulos, "Competitive Procurement of Ancillary Services by an Independent System Operator," IEEE Transactions on Power Systems, vol. 14, no. 2, pp 498-504,May 1999.

[6] J.C. Smith et al, "Impact of variable renewable energy on US electricity markets," Proceedings of IEEE PES General Meeting, Minneapolis, MN, July 2010.

[7] E. Ela, M. Milligan, and B. Kirby, "Operating Reserves and Variable Generation," NREL/TP-5500-51928, August 2011.

[8] V. Vittal, J. McCalley, V. Ajjarapu, and U. Shanbhag, "Impact of Increased DFIG Wind Penetration on Power Systems and Markets," PSERC Publication 09-10, October 2009.

[9] N.W. Miller K. Clark, and M. Shao, "Impact of frequency responsive wind plant controls on grid performance," Proceedings of the 9th Annual Large-Scale Integration of Wind Power into Power Systems and Transmission Networks for Offshore Wind Power Plant, Quebec, Canada, October 2010.

[10] I. Erlich, \& M. Wilch, "Primary frequency control by wind turbines," Proceedings of the IEEE Power and Energy Society General Meeting, Minneapolis, MN, July 2010.

[11] N. R. Ullah, T. Thiringer, D. Karlsson, "Voltage and transient stability support by wind farms complying with the E. ON Netz grid code," IEEE Transactions on Power Systems, vol. 22, no. 4, pp 1647-1656, November 2007.

[12] Promotion of wholesale competition through open access nondiscriminatory transmission services by public utilities and recovery of stranded costs by public utilities and transmitting utilities, Order No. 888, FERC Stats. \& Regs. Issued April 1996.

[13] S. Fink, J. Rodgers, and K. Porter, "Wind Power and Electricity Markets," August $2009 . \quad$ Available: http://www.uwig.org/WindinMarketsTableSept09.pdf.

[14] North American Electric Reliability Corporation, "Reliability Standards for the Bulk Electric Systems of North America," October 2011.

[15] WECC, "Western Electricity Coordinating Council minimum operating reliability criteria," April 2005.

[16] Northeast Power Coordinating Council, A-06 Operating Reserve Criteria, December 2008, section 3.2.

[17] Electric Reliability Council of Texas, "ERCOT Methodologies for Determining Ancillary Service Requirements," 2009.

[18] B. Kirby and E. Hirst, "Customer-Specific Metrics for the Regulation and Load-Following Ancillary Services," ORNL/CON-474, Oak Ridge National Laboratory, Oak Ridge TN, January 2000.

[19] Enernex Corporation, "Eastern Wind Integration and Transmission Study," Prepared for the National Renewable Energy Laboratory, January 2010.

[20] GE Energy, "Western Wind and Solar Integration Study," Prepared for the National Renewable Energy Laboratory, May 2010.

[21] R. Doherty and M. O'Malley, "A new approach to quantify reserve demand in systems with significant installed wind capacity," IEEE Transactions on Power Systems, vol. 20, no. 2, pp. 587-595, May 2005.

[22] M. Lazarewicz, A. Rojas, "Grid frequency regulation by recycling electrical energy in flywheels," Proceedings of Power Engineering Society General Meeting, Denver, CO, June 2004.

[23] B. Kirby, M. Milligan, and E. Ela, "Providing minute-to-minute regulation from wind plants," Proceedings of the 9th Annual LargeScale Integration of Wind Power into Power Systems and Transmission Networks for Offshore Wind Power Plant, Quebec, Canada, October 2010.

[24] J. Liang, S. Grijalva, and R. Harley, "Increased wind revenue and system security by trading wind power in energy and regulation reserve markets," IEEE Transactions on Sustainable Energy, vol. 2, no. 3, pp. 340-347, July 2011.

[25] B. Kirby, M. Milligan, "Examination of Capacity and Ramping Impacts of Wind Energy on Power Systems," NREL/TP-500-42872, July 2008.

[26] Western Electricity Coordinating Council, "White Paper on Frequency Responsive Reserve Standard," April 2005.

[27] Report: ENTSO-E, UCTE Operational Handbook Policy 1, LoadFrequency Control and Performance, March 2009.

[28] R. Schulz, "Modeling of governing response in the Eastern Interconnection," Proceedings of the IEEE Power Engineering Society Winter Meeting, New York, NY, February 1999.

[29] N. Miller, K. Clark, M. Shao, Frequency Responsive Wind Plant Controls: Impacts on Grid Performance. IEEE PES General Meeting, Detroit, July, 2011.
[30] J. Brisebois, N. Aubut, Wind Farm Inertia Emulation to Fulfill HydroQuebec's Specific Need. IEEE PES General Meeting, Detroit, July, 2011.

[31] B. Kirby and E. Hirst, "Ancillary-Service Details: Voltage Control," ORNL/CON-453, Oak Ridge National Laboratory, Oak Ridge TN, December 1997.

[32] N. Navid, G. Rosenwald, and D. Chatterjee, "Ramp Capability for Load Following in the MISO Markets," Version 1.0, July 2011.

\section{BIOGRAPHIES}

Erik Ela (M'06) received the B.S.E.E degree from Binghamton University and the M.S. degree in Power Systems at the Illinois Institute of Technology. He joined the NREL grid integration team to work on different wind integration issues. Erik previously worked for the New York ISO developing and improving products in the energy markets and operations areas. Erik is a member of IEEE and the Power and Energy Society.

Brendan Kirby (SM '76) is a private consultant with numerous clients including AWEA, National Renewable Energy Laboratory, Oak Ridge National Laboratory, EPRI and others. He recently retired as a senior researcher with the Oak Ridge National Laboratory's Power Systems Research Program. He has 34 years of electric utility experience and has published over 120 papers, articles, and reports on ancillary services, wind integration, restructuring, the use of responsive load as a bulk system reliability resource, and power system reliability. He has a patent for responsive loads providing real-power regulation and is the author of a NERC certified course on Introduction to Bulk Power Systems: Physics / Economics / Regulatory Policy.

Nivad Navid is consulting engineer in Market Development and Analysis department at MISO. Nivad held various positions in MISO working on reliability, market and seams projects. Before joining MISO, he held positions in Siemens, CAE Electronics and Power engineering consultants. He has broad experience ranging a wide variety from the utility operation to the system planning, operation, reliability, security and design. His current interests are: electricity markets, renewable generation, storage resources and SMART grid. He received his $\mathrm{PhD}$ from McGill University, Montreal, Canada in 1995. He is a senior member of IEEE.

J. Charles Smith (SM '85) is the Executive Director of the Utility Wind Integration Group. He is a Senior Member of the IEEE PES and a member of CIGRE. He received his BSME and MS degrees from MIT in 1970. He currently serves as the Executive Director of the Utility Wind Integration Group (UWIG). Previously, he served as President of Electrotek Concepts, a power engineering consulting firm. He has 35 years of experience in the electric power industry. 